\title{
The contribution of orthography to spoken word production: Evidence from Mandarin Chinese
}

\author{
YANCHAO BI AND TAO WEI \\ Beijing Normal University, Beijing, China \\ NiELS JANSSEN \\ CNRS and Université de Provence, Marseille, France \\ AND \\ ZAIZHU HAN \\ Beijing Normal University, Beijing, China
}

\begin{abstract}
A recent debate in the language production literature concerns the influence of a word's orthographic information on spoken word production and the extent to which this influence is modulated by task context. In the present study, Mandarin Chinese participants produced sets of words that shared orthography $(\mathrm{O}+\mathrm{P}-)$, phonology $(\mathrm{O}-\mathrm{P}+)$, or orthography and phonology $(\mathrm{O}+\mathrm{P}+)$, or were unrelated $(\mathrm{O}-\mathrm{P}-)$, in the context of a reading, associative naming, or picture naming task. Shared phonology yielded facilitation effects in all three tasks, but only in the reading task was this phonological effect modulated by shared orthography. Shared orthography by itself $(\mathrm{O}+\mathrm{P}-)$ revealed inhibitory effects in reading, but not in associative naming or in picture naming. These results suggest that a word's orthography information influences spoken word production only in tasks that rely heavily on orthographic information.
\end{abstract}

The degree to which processing of information from one modality interacts with information from another modality is a topic of general interest in cognitive psychology. Within speech comprehension, classic evidence revealing such an interaction between different modalities comes from the study of Seidenberg and Tanenhaus (1979). These authors showed that rhyme judgments on auditorily presented words were faster when those words were orthographically related (e.g., pie-tie) than when they were orthographically unrelated (e.g., pie-bye). Recent studies have investigated the influence of a word's orthographic information on speech production (Alario, Perre, Castel, \& Ziegler, 2007; J.-Y. Chen \& T.-M. Chen, 2007; T.-M. Chen \& J.-Y. Chen, 2006; Damian \& Bowers, 2003; Roelofs, 2006). In the present study, we exploited a property of Mandarin Chinese that allowed us to directly assess the independent contributions of a word's orthographic and phonological information to speech production.

The effect of orthography on speech production has been investigated through the use of various adaptations of the implicit priming technique. In experiments using this technique, participants produce responses in small sets. The relationships among the responses in a set can be related (homogeneous) or unrelated (heterogeneous). In one variant of this technique, associative naming, the participants first learn to associate sets of word pairs (e.g., desert-camel); in the experiment proper, they produce a vocal response (i.e., camel) on the basis of the associated cue word (i.e., desert). A standard finding is the formpreparation effect (see, e.g., Meyer, 1990, 1991). When the target words in a set share orthographic and phonological properties $(\mathrm{O}+\mathrm{P}+$; e.g., desert-camel, tea-coffee, sofa-cushion), response production latencies are faster than when they are unrelated $(\mathrm{O}-\mathrm{P}-$; e.g., desert-camel, wander-gypsy, sofa-cushion).

Using associative naming, Damian and Bowers (2003) showed that English participants' response latencies to targets that shared phonology, but not orthography $(\mathrm{O}-\mathrm{P}+$; e.g., dog-kennel, tea-coffee, sofa-cushion), were slower than those to targets that shared phonology and orthography $(\mathrm{O}+\mathrm{P}+)$, and that they did not differ from unrelated targets $(\mathrm{O}-\mathrm{P}-)$. This modulation of the form-preparation effect by orthographic information has been referred to in the literature as the orthographic inconsistency effect. On the basis of this result, the authors argued for a language production system in which orthographic and phonological information interact.

In subsequent studies, researchers have failed to replicate this effect and have attempted to understand the discrepancy from two perspectives: (1) Was the effect observed by Damian and Bowers (2003) language specific (English), and (2) was it task specific (associative naming)? First, Roelofs (2006) examined whether the orthographic inconsistency effect in speech production is influenced by the transpar-

Z.Han, zzhhan@bnu.edu.cn 
ency of the language's orthography-phonology correspondence (OPC). However, studies have reported that the orthographic inconsistency effect does not appear in Dutch (Roelofs, 2006) - a language with more transparent OPC than English-French (Alario et al., 2007), or Mandarin Chinese (J.-Y. Chen \& T.-M. Chen, 2007; T.-M. Chen \& J.-Y. Chen, 2006; see also J.-Y. Chen, T.-M. Chen, \& Dell, 2002), which are equally as transparent as or less transparent than English. Second, Roelofs explored whether the effect is task specific by examining the orthographic inconsistency effect in three tasks of implicit priming that differed in the extent to which they emphasized the use of orthographic processing: reading, associative naming, and picture naming. ${ }^{1}$ The results revealed an orthographic inconsistency effect in reading, but not in the other two tasks. Although this suggests that the orthographic inconsistency effect is task specific and that it depends on the degree to which the task requires orthographic processing, it leaves unexplained why Damian and Bowers observed the effect in the associative naming task.

Thus, the experimental circumstances that have led to the observation of the orthographic inconsistency effect are not clear. One reason why it is not more readily observed might lie in the way it has typically been assessed. The orthographic inconsistency effect is measured by comparing sets of target words in which phonology and orthography are shared with sets where only phonology is shared (i.e., $\mathrm{O}+\mathrm{P}+$ vs. $\mathrm{O}-\mathrm{P}+$ ). It is possible that, in such a comparison, the phonological effect overshadows the orthographic effect, and the orthographic inconsistency effect is observed rather inconsistently. Another way to assess the orthographic effect on speech production could be to consider the effect of pure orthography, the effect of a word's orthography on speech production in the absence of any contribution from phonology (i.e., $\mathrm{O}+\mathrm{P}-$ vs. $\mathrm{O}-\mathrm{P}-$ ).

In two previous studies using the associative naming task, it was suggested that pure orthographic relatedness does not play a role in speech production. Damian and Bowers (2003, Experiment 4) compared an O+P- condition with an $\mathrm{O}-\mathrm{P}-$ condition and did not observe any significant difference. However, the findings might not be conclusive, due to the properties of the target language. In English, grapheme-phoneme correspondence is generally high, which may complicate the selection of materials for the $\mathrm{O}+\mathrm{P}-$ condition and lead to the selection of noisy materials. Indeed, the other finding in that study, the orthographic inconsistency effect, was not replicated in subsequent studies. In a larger study on morphological processing in Chinese (T.-M. Chen \& J.-Y. Chen, 2006), Experiment 1B can also be viewed as being an assessment of the pure orthographic effect. Two conditions that contained four-item sets were compared: One condition had each set include three targets that shared orthography and phonology $(\mathrm{O}+\mathrm{P}+)$ and one target that shared only orthography $(\mathrm{O}+\mathrm{P}-)$. The other condition included three targets that shared orthography and phonology $(\mathrm{O}+\mathrm{P}+)$ and one unrelated target $(\mathrm{O}-\mathrm{P}-)$. If orthography plays a role in speech production, one would expect that, relative to unrelated baselines, a larger preparation effect should be observed in the first condition. Contrary to this expectation, the results revealed comparable facilitation effects (38 and $28 \mathrm{msec}$, respectively). Note, however, that this design is not very powerful in detecting an effect of pure orthography, given that, out of the four targets in each set, only one target shared orthography but not phonology.

The aim of the research presented here was twofold. First, we investigated whether the effect of pure orthography would be reliably observed in the associative naming task. Second, following Roelofs (2006), we examined whether the effect of pure orthography would vary as a function of task demands by employing three tasks that used the same implicit priming design: reading, associative naming, and picture naming. The independent contributions of a word's orthographic and phonological information on speech production were investigated by exploiting a particular property of Mandarin Chinese. Mandarin Chinese uses a logographic writing system in which orthography-phonology mapping is highly opaque. This property allows for the orthogonal manipulation of a word's orthographic and phonological properties. In addition to the pure orthographic effect, we also report the orthographic inconsistency effect $(\mathrm{O}-\mathrm{P}+\mathrm{vs} . \mathrm{O}+\mathrm{P}+)$ and the effect of pure phonology $(\mathrm{O}-\mathrm{P}+$ vs. $\mathrm{O}-\mathrm{P}-)$.

\section{EXPERIMENTS 1, 2, AND 3 \\ Reading, Associative Naming, and Picture Naming}

\section{Method}

Participants. A total of 54 native speakers of Mandarin Chinese served as paid participants, with 18 participants in each experiment: Experiment 1 (reading), Experiment 2 (associative naming), and Experiment 3 (picture naming). All of the participants were students at Beijing Normal University and all had normal or corrected-tonormal vision.

Materials. First, we selected 12 triplets of concrete, depictable, disyllabic Mandarin Chinese words to serve as the target words in all three experiments. There were 4 triplets in each of three conditions. In the $\mathrm{O}+\mathrm{P}+$ condition, the first syllables of the words in each triplet shared both orthography and phonology (e.g., 沙发, “sha1 fa1," sofa; 砂子, “sha1zi," sand; 纱布, “sha1bu4," gauze). In the O-P+ condition, only phonology was shared (e.g., 珍珠, “zhen1zhu1,” pearl; 侦探, “zhen1 1 tan 4 ,” detective; 针管, “zhen1 guan3,” needle). In the $\mathrm{O}+\mathrm{P}-$ condition, only orthography was shared (e.g., 蜡烛, “la4zhu2,” candle; 醋瓶, “cu4ping2,” vinegar bottle; 借条, “jie4tiao2,” receipt for a loan). Orthographically related words shared at least half of the logographemes ${ }^{2}$ in the same positions, and phonologically related words were homophones. The 4 triplets in each of the three related conditions were then re-paired to form 4 unrelated triplets serving as the corresponding control condition $(\mathrm{O}-\mathrm{P}-)$ for each related condition. Therefore, the stimuli set had a structure of 3 (type of related condition: $\mathrm{O}+\mathrm{P}+, \mathrm{O}-\mathrm{P}+, \mathrm{O}+\mathrm{P}-$ ) $\times 2$ (relatedness: related, unrelated), with 4 triplets in each cell (see the Appendix).

Task settings for the reading, associative naming, and picture naming tasks were similar to those of Roelofs (2006). In the reading task, target words were read directly, whereas, in the associative naming task, cue words were selected for each of the targets (e.g., 家具, furniture, for the target 沙发, couch), and the participants produced the target words upon seeing the cue words. In the picture naming task, the corresponding pictures for the targets were presented. These pictures were selected from various sources, including Snodgrass and Vanderwart (1980).

In each experiment, every triplet was repeated seven times, forming a miniblock. Trial presentation in each miniblock was pseudo- 
randomized, so that there were no identical triplets on consecutive trials. The first repetition in each miniblock was treated as practice, and the remaining six repetitions were considered to be experimental trials for analyses. The four triplets in the same condition comprised a "superblock." Each experiment therefore contained six superblocks (144 experimental trials in total), including three related and three unrelated ones. Each participant saw all six superblocks once. The order of the six superblocks was counterbalanced across participants, using an incomplete Latin square method, so that each superblock occurred at each presentation position an equal number of times.

Apparatus. The DMDX program (Forster \& Forster, 2003) was used to present the stimuli and record reaction times (RTs).

Procedure. The participants were tested individually in a dimly lit, soundproofed room and were seated about $60 \mathrm{~cm}$ from the front of the screen. The general procedure for each experiment was similar to that used in Roelofs (2006). There were always two parts in each miniblock: a learning session and an experimental session.

For Experiment 1 (reading), in the learning session, the participants read aloud the triplets of target words in sequence. In the experimental session, one word was presented on each trial and was read aloud.

For Experiment 2 (associative naming), the learning session consisted of memorizing the cue target pairs for each triplet. In the experimental session, a cue word was presented in the center of the screen and the participant would speak aloud the corresponding target.

For Experiment 3 (picture naming), the learning session consisted of participants naming the picture triplets in sequence. If the response was not the expected target word, the experimenter made a correction and asked the participant to name the picture with the designated name. In the experimental session, one picture was presented in every trial, and the participants named the picture aloud.

In all learning sessions, the stimuli stayed on the screen until the participant pressed the space bar. In the experimental sessions, a trial started with the stimulus being presented in the middle of the white background, and the stimulus stayed on the screen for $3 \mathrm{sec}$ or until the participant produced a vocal response. The trial intervals were $1 \mathrm{sec}$. The words were presented in 36-point Song font in Experiments 1 and 2 (reading and associative naming, respectively), and the pictures were scaled to fit a $245 \times 245$ pixel square in Experiment 3 (picture naming). Each experiment lasted about $30 \mathrm{~min}$, with two breaks.

\section{Results and Discussion}

For all three experiments, the following types of responses were counted as errors and were excluded from the analyses: incorrect responses, dysfluencies and stuttering, voice key failures, and latencies shorter than $200 \mathrm{msec}$ and longer than 2,000 msec. The total percentages of data points eliminated were $0.7 \%$ (reading), 1.9\% (associative naming), and $1.4 \%$ (picture naming), respectively. RTs that deviated from a participant's mean by more than 3 standard deviations were replaced by the cutoffs.

Given that the error rates were rather low in the whole experiments, statistical analyses were carried out on the RTs only. A 3 (type of related condition: $\mathrm{O}+\mathrm{P}+, \mathrm{O}-\mathrm{P}+$, $\mathrm{O}+\mathrm{P}-$ ) $\times 2$ (relatedness: related, unrelated) ANOVA was conducted for each experiment. Both variables were within-participants variables in the participant analyses $\left(F_{1}\right)$. In the item analyses $\left(F_{2}\right)$, "type of related condition" was a between-items variable, and "relatedness" was a within-items variable. The pure effect of phonology and the pure effect of orthography were tested by comparing the $\mathrm{O}-\mathrm{P}+$ and $\mathrm{O}+\mathrm{P}-$ conditions against their corresponding controls $(\mathrm{O}-\mathrm{P}-)$. To assess the orthographic effect on top of the phonological effect, we employed a 2 (type of related condition: $\mathrm{O}+\mathrm{P}+, \mathrm{O}-\mathrm{P}+$ ) $\times 2$ (related-
Table 1

Mean Reaction Times ( $M$, in Milliseconds), Standard Deviations (SDs), and Error Rates (Err, in Percentage) in Experiments 1, 2, and 3

\begin{tabular}{|c|c|c|c|c|c|c|c|c|c|c|}
\hline & & \multicolumn{3}{|c|}{ Experiment 1} & \multicolumn{3}{|c|}{ Experiment 2} & \multicolumn{3}{|c|}{ Experiment 3} \\
\hline \multicolumn{2}{|c|}{ Group } & $M$ & $S D$ & Err & $M$ & $S D$ & Err & $M$ & $S D$ & Err \\
\hline \multirow[t]{2}{*}{$\mathrm{O}+\mathrm{P}+$} & $\mathrm{R}$ & 453 & 67 & 1.1 & 706 & 80 & 2.5 & 573 & 71 & 1.8 \\
\hline & UR & 498 & 52 & 0.9 & 765 & 64 & 1.7 & 609 & 78 & 1.5 \\
\hline \multirow[t]{2}{*}{$\mathrm{O}-\mathrm{P}+$} & $\mathrm{R}$ & 455 & 59 & 0.6 & 692 & 73 & 1.8 & 542 & 72 & 1.5 \\
\hline & UR & 486 & 45 & 0.6 & 734 & 63 & 1.8 & 589 & 69 & 0.8 \\
\hline \multirow[t]{2}{*}{$\mathrm{O}+\mathrm{P}-$} & $\mathrm{R}$ & 523 & 58 & 0.3 & 763 & 59 & 1.9 & 608 & 79 & 1.4 \\
\hline & UR & 503 & 53 & 0.5 & 752 & 56 & 1.7 & 607 & 80 & 1.2 \\
\hline
\end{tabular}

Note-R, related condition; UR, unrelated condition. ${ }^{*} p<.05$.

ness: related, unrelated) ANOVA on the following four cells: $\mathrm{O}+\mathrm{P}+, \mathrm{O}+\mathrm{P}+$ 's control $(\mathrm{O}-\mathrm{P}-), \mathrm{O}-\mathrm{P}+$, and $\mathrm{O}-\mathrm{P}+$ 's control $(\mathrm{O}-\mathrm{P}-)$.

Overviews of mean RTs per condition and corresponding statistics are presented in Tables 1 and 2. In all three experiments, the main effects of relatedness and types of relatedness were significant both by subject and by item, as was their interaction. In reading (Experiment 1), when the word targets shared both phonological and orthographic properties in a set, they were read significantly faster than those in a corresponding heterogeneous set. The pure phonological condition also produced a significant facilitation effect that was smaller than the effect of the $\mathrm{O}+\mathrm{P}+$ condition, as was revealed by the significant orthographic inconsistency effect. When the targets shared only orthography, however, there was a significant inhibitory effect.

In associative naming (Experiment 2), in comparison with the unrelated baseline, when targets were both phonologically and orthographically related, there was a significant facilitation effect, which was comparable in size to the facilitation effect in sets where targets were only phonologically related (orthographic inconsistency effect not significant). The orthographically related sets did not show any significant effect on production, in comparison with the corresponding heterogeneous group.

The results for picture naming (Experiment 3) parallel those for associative naming (Experiment 2).

We further carried out three-way interaction analyses, treating the experimental task as a between-participants, within-items variable, in order to elucidate the effect of orthography across tasks. The pure orthographic effect $(\mathrm{O}+\mathrm{P}-, \mathrm{O}-\mathrm{P}-) \times$ task (reading, associative naming, picture naming) interaction was significant by items and not by participants $\left[F_{1}(2,51)=1.18, M S_{\mathrm{e}}=838, p=\right.$ $\left..315 ; F_{2}(2,22)=6.63, M S_{\mathrm{e}}=101, p<.01\right]$. The orthographic inconsistency effect [type of relationship $(\mathrm{O}+\mathrm{P}+$, $\mathrm{O}+\mathrm{P}-) \times$ relatedness (related, unrelated) $] \times$ task $($ reading, associative naming, picture naming) interaction was marginally significant by item, but not by participant $\left[F_{1}(2,51)=1.40, M S_{\mathrm{e}}=840, p=.256 ; F_{2}(2,44)=2.50\right.$, $\left.M S_{\mathrm{e}}=280, p=.094\right]$. The overall trend of interaction between the orthographic effects and task confirms the results that the effect of orthography is modulated by the specific requirements of the task at hand.

Taken together, and in line with previous studies, in all three tasks, we found the standard form-preparation ef- 
Table 2

Results of Statistical Analyses of Reaction Times in Experiments 1, 2, and 3

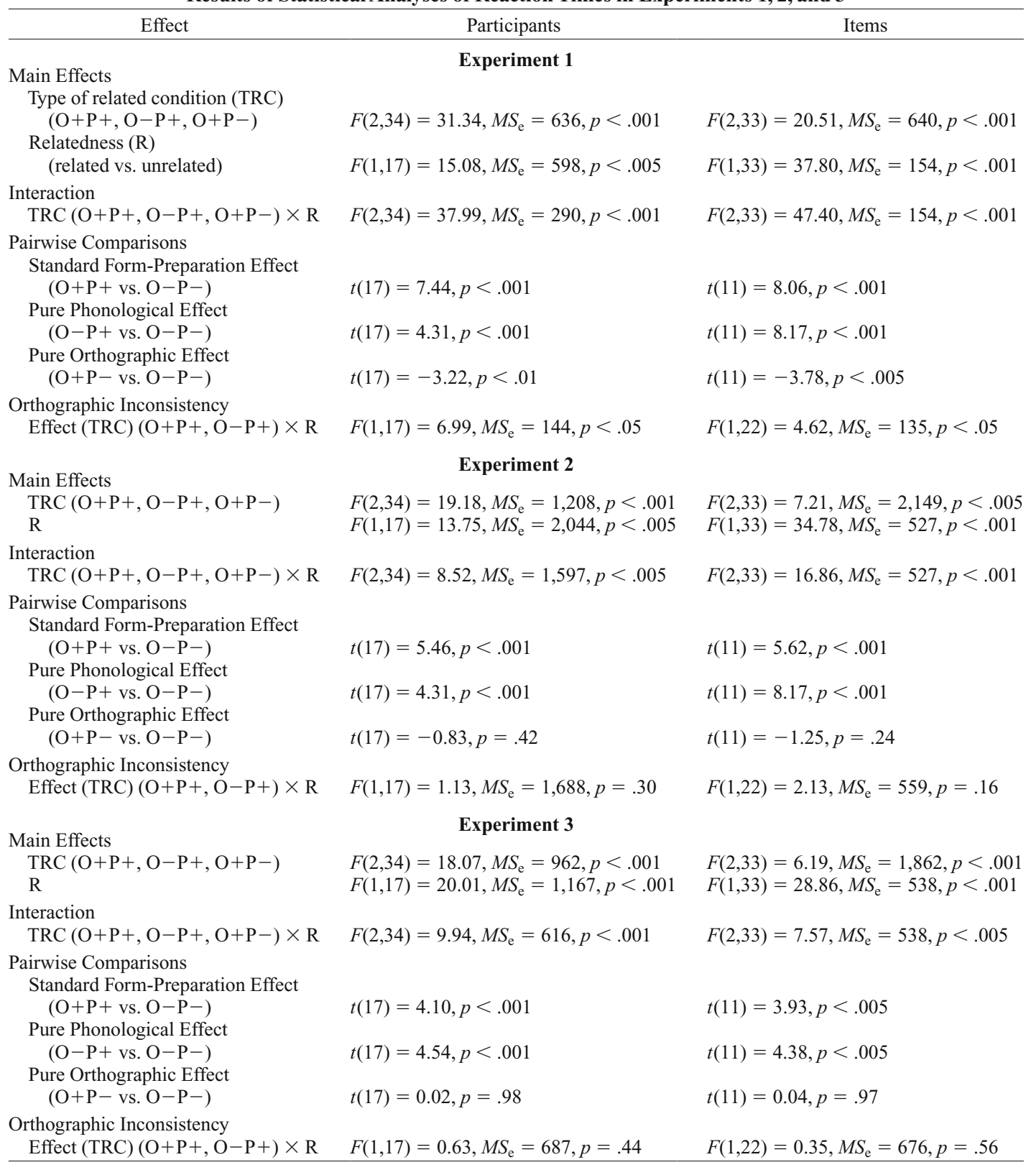

fect $(\mathrm{O}+\mathrm{P}+$ vs. O-P-; e.g., Meyer, 1990, 1991) and a facilitatory effect of pure phonology $(\mathrm{O}-\mathrm{P}+\mathrm{vs} . \mathrm{O}-\mathrm{P}-$; e.g., Alario et al., 2007; Roelofs, 2006). Furthermore, as was reported by Roelofs, in the reading task, we found an effect of orthographic inconsistency $(\mathrm{O}+\mathrm{P}+\mathrm{vs} . \mathrm{O}-\mathrm{P}+)$, but not in the associative naming or picture naming tasks. Finally, in the reading task, we found inhibitory effects of pure orthography $(\mathrm{O}+\mathrm{P}-\mathrm{vs}$. $\mathrm{O}-\mathrm{P}-)$, but not in the associative naming or picture naming tasks.

\section{GENERAL DISCUSSION}

Previous studies have only reported the effect of orthography in speech production in restricted circum- stances (Alario et al., 2007; J.-Y. Chen \& T.-M. Chen, 2007; J.-Y. Chen et al., 2002; T.-M. Chen \& J.-Y. Chen, 2006; Damian \& Bowers, 2003; Roelofs, 2006). We suggested that the orthographic effect in these studies was not fully evaluated, because, in most studies, it was assessed in the context of the phonological effect. In the present study, we circumvented this problem by looking at a pure orthographic effect, contrasting the $\mathrm{O}+\mathrm{P}-$ and $\mathrm{O}-\mathrm{P}-$ conditions in three variants of implicit priming. Pure orthography affected naming latencies in a reading task, but not in associative naming or picture naming tasks.

In line with previous studies, our results also show no effect of orthographic inconsistency $(\mathrm{O}+\mathrm{P}+\mathrm{vs} . \mathrm{O}-\mathrm{P}+)$ in picture naming or associative naming (Alario et al., 
2007; J.-Y. Chen \& T.-M. Chen, 2007; J.-Y. Chen et al., 2002; T.-M. Chen \& J.-Y. Chen, 2006; Roelofs, 2006). Furthermore, there was also no effect of pure orthographic relatedness $(\mathrm{O}+\mathrm{P}-$ vs. $\mathrm{O}-\mathrm{P}-)$ in the picture naming or associative naming tasks.

Other studies have reported no effect of pure orthography in speech production using the associative naming task (T.-M. Chen \& J.-Y. Chen, 2006; Damian \& Bowers, 2003). As we argued in the introduction, the results from these studies are not conclusive. In Damian and Bowers, material selected might have been noisy, and in T.-M. Chen and J.-Y. Chen, the design may have lacked sufficient power to detect the effect.

Finally, our results are in line with Roelofs's (2006) argument that the orthographic effect depends on the extent to which the task emphasizes the use of orthographic information. The pure orthographic and orthographic inconsistency effects were not observed in the associative naming and picture naming tasks, but they were observed in the reading task. Note that the orthographic inconsistency effect was facilitatory (see also Roelofs, 2006), but that the pure orthographic effect was inhibitory. This pure orthographic effect is consistent with findings reported in the visual word processing literature, where inhibitory effects have been reported in word reading and lexical decision tasks when inconsistent phonological codes were activated from shared orthographic properties (e.g., PINT-MINT vs. unrelated controls; Glushko, 1979).

To conclude, we observed that the orthographic relatedness among responses in production did not affect production performance when orthographic relatedness was present by itself or when it was presented with the phonological relatedness. In reading tasks, salient orthographic effects were yielded. Such results contrast with the findings in the literature, in which interactivity was obtained across modalities (e.g., orthographic inconsistency effect in processing auditory words; see Dijkstra, Roelofs, \& Fieuws, 1995; Seidenberg \& Tanenhaus, 1979; Ziegler \& Ferrand, 1998; phonological effect on processing visual words; see Stone, Vanhoy, \& Van Orden, 1997; Ziegler, Montant, \& Jacobs, 1997). We suspect that such interactivity might only occur when the source of the activation is a word input and not when it requires lexical selection from concepts or associations (associative naming and picture naming; Alario et al., 2007; Roelofs, 2006; for a similar pattern in a comparable task, see Franck, Bowers, Frauenfelder, \& Vigliocco, 2003).

\section{AUTHOR NOTE}

The research reported here was supported by grants from PCSIRT (IRT0710), NSFC (30700224), and BJSF (7082051) to Y.B. We thank Wen Xu, Lili Deng, and Jingyi Geng for testing our participants. Correspondence concerning this article should be addressed to Z. Han, State Key Laboratory of Cognitive Neuroscience and Learning, Beijing Normal University, Beijing, 100875, China (e-mail: zzhhan@bnu.edu.cn).

\section{REFERENCES}

Alario, F.-X., Perre, L., Castel, C., \& Ziegler, J. C. (2007). The role of orthography in speech production revisited. Cognition, 102, 464475. doi:10.1016/j.cognition.2006.02.002
Chen, J.-Y., \& Chen, T.-M. (2007). Form encoding in Chinese word production does not involve morphemes. Language \& Cognitive Processes, 22, 1001-1020. doi:10.1080/01690960701190249

Chen, J.-Y., Chen, T.-M., \& Dell, G. S. (2002). Word-form encoding in Mandarin Chinese as assessed by the implicit priming task. Journal of Memory \& Language, 46, 751-781. doi:10.1006/ jmla.2001.2825

Chen, T.-M., \& CHEN, J.-Y. (2006). Morphological encoding in the production of compound words in Mandarin Chinese. Journal of Memory \& Language, 54, 491-514. doi:10.1016/j.jml.2005.01.002

DAMIAN, M. F., \& BowERs, J. S. (2003). Effects of orthography on speech production in a form-preparation paradigm. Journal of Memory \& Language, 49, 119-132. doi:10.1016/S0749-596X(03)00008-1

Dijkstra, T., Roelofs, A., \& Fieuws, S. (1995). Orthographic effects on phoneme monitoring. Canadian Journal of Experimental Psychology, 49, 264-271. doi:10.1037/1196-1961.49.2.264

Forster, K. I., \& Forster, J. C. (2003). DMDX: A Windows display program with millisecond accuracy. Behavior Research Methods, Instruments, \& Computers, 35, 116-124.

Franck, J., Bowers, J. S., Frauenfelder, U. H., \& Vigliocco, G. (2003). Orthographic influences on agreement: A case for modalityspecific form effects on grammatical encoding. Language \& Cognitive Processes, 18, 61-79. doi:10.1080/01690960143000452

GLushKo, R. J. (1979). The organization and activation of orthographic knowledge in reading aloud. Journal of Experimental Psychology: Human Perception \& Performance, 5, 674-691. doi:10.1037/0096 $-1523.5 .4 .674$

Han, Z. Z., Zhang, Y. M., ShU, H., \& BI, Y. C. (2007). The orthographic buffer in writing Chinese characters: Evidence from a dysgraphic patient. Cognitive Neuropsychology, 24, 431-450. doi: $10.1080 / 02643290701381853$

LAW, S.-P., \& LEUNG, M.-T. (2000). Structural representations of characters in Chinese writing: Evidence from a case of acquired dysgraphia. Psychologia, 43, 67-83.

MeYer, A. S. (1990). The time course of phonological encoding in language production: The encoding of successive syllables of a word. Journal of Memory \& Language, 29, 524-545. doi:10.1016/0749 $-596 \mathrm{X}(90) 90050-\mathrm{A}$

Meyer, A. S. (1991). The time course of phonological encoding in language production: Phonological encoding inside a syllable. Journal of Memory \& Language, 30, 69-89. doi:10.1016/0749 $-596 \times(91) 90011-8$

RoELOFS, A. (2006). The influence of spelling on phonological encoding in word reading, object naming, and word generation. Psychonomic Bulletin \& Review, 13, 33-37.

Seidenberg, M. S., \& Tanenhaus, M. K. (1979). Orthographic effects on rhyme monitoring. Journal of Experimental Psychology: Human Learning \& Memory, 5, 546-554. doi:10.1037/0278-7393.5.6.546

Snodgrass, J. G., \& VANDERWART, M. (1980). A standardized set of 260 pictures: Norms for name agreement, image agreement, familiarity, and visual complexity. Journal of Experimental Psychology: Human Learning \& Memory, 6, 174-215. doi:10.1037/0278-7393.6.2.174

Stone, G. O., Vanhoy, M. D., \& Van Orden, G. C. (1997). Perception is a two-way street: Feedforward and feedback phonology in visual word recognition. Journal of Memory \& Language, 36, 337-359. doi:10.1006/jmla.1996.2487

Ziegler, J. C., \& FerRand, L. (1998). Orthography shapes the perception of speech: The consistency effect in auditory word recognition. Psychonomic Bulletin \& Review, 5, 683-689.

Ziegler, J. C., Montant, M., \& Jacobs, A. M. (1997). The feedback consistency effect in lexical decision and naming. Journal of Memory \& Language, 37, 533-554. doi:10.1006/jmla.1997.2525

\section{NOTES}

1. In reading and picture naming, the experimental constructions were identical to that of associative naming, except that no cue words were included, and targets were directly presented as words (reading) or pictures (picture naming).

2. Smallest visual/spatial components in Chinese characters (see Han, Zhang, Shu, \& Bi, 2007; Law \& Leung, 2000). 
APPENDIXA

Stimuli (Targets) Used in Experiments 1, 2, and 3

\begin{tabular}{|c|c|c|c|}
\hline Group & Set & Related Condition & Unrelated Condition $(\mathrm{O}-\mathrm{P}-)$ \\
\hline $\mathrm{O}+\mathrm{P}+$ & 1 & $\begin{array}{l}\text { 沙发,/sha1fa1/, sofa } \\
\text { 砂子,/sha1zi/, sand } \\
\text { 纱布,/sha1bu4/, gauze } \\
\text { 峰峦,/feng1luan2/, mountain } \\
\text { 蜂窝,//feng1wo1/, beehive } \\
\text { 烽火,/feng1huo3/, signal fire } \\
\text { 玛瑙,/ma3nao3/, agate } \\
\text { 码头,/ma3tou2/, dock } \\
\text { 蚂蚁,/ma3yi3/, ant } \\
\text { 驼背,/tuo2bei4/, crookback } \\
\text { 鸟它鸟,/tuo2niao3/, ostrich } \\
\text { 陀螺,/tuo2luo2/, peg-top }\end{array}$ & $\begin{array}{l}\text { 烽火,/feng1huo3/, signal fire } \\
\text { 砂子,/sha1zi/, sand } \\
\text { 蚂蚁,/ma3yi3/, ant } \\
\text { 沙发,/sha1fa1/, sofa } \\
\text { 驼背,/tuo2bei4/, crookback } \\
\text { 蜂窝, /feng1wo1/, beehive } \\
\text { 峰峦,/feng1luan2/, mountain } \\
\text { 码头,/ma3tou2/, dock } \\
\text { 鸟它岛,/tuo2niao3/, ostrich } \\
\text { 玛瑙,/ma3nao3/, agate } \\
\text { 陀螺,/tuo2luo2/, peg-top } \\
\text { 纱布,/sha1bu4/, gauze }\end{array}$ \\
\hline $\mathrm{O}-\mathrm{P}+$ & 1 & $\begin{array}{l}\text { 河流, /he2liu2/, river } \\
\text { 禾苗,/he2miao2/, seedling } \\
\text { 盒子,/he2zi/, box } \\
\text { 玫瑰,/mei2gui1/, rose } \\
\text { 眉毛,/mei2mao2/, eyebrow } \\
\text { 煤炭,/mei2tan4/, coal } \\
\text { 珍珠,/zhen1zhu1/, pearl } \\
\text { 侦探,/zhen1tan4/, detective } \\
\text { 针管,/zhen1guan3/, needle } \\
\text { 蔬菜,/shu1cai4/, vegetable } \\
\text { 书本,/shu1ben3/, book } \\
\text { 梳子,/shu1zi/, comb }\end{array}$ & $\begin{array}{l}\text { 玫瑰, /mei2gui1/, rose } \\
\text { 盒子,/he2zi/, box } \\
\text { 侦探, /zhen1tan4/, detective } \\
\text { 书本, /shu1ben3/, book } \\
\text { 煤炭, /mei2tan4/, coal } \\
\text { 珍珠,/zhen1zhu1/, pearl } \\
\text { 禾苗, /he2miao2/, seedling } \\
\text { 眉毛, /mei2mao2/, eyebrow } \\
\text { 梳子,/shu1zi/, comb } \\
\text { 针管, /zhen1guan3/, needle } \\
\text { 蔬菜,/shu1cai4/, vegetable } \\
\text { 河流,/he2liu2/, river }\end{array}$ \\
\hline $\mathrm{O}+\mathrm{P}-$ & 4 & $\begin{array}{l}\text { 蜡烛, /la4zhu2/, candle } \\
\text { 醋瓶, /cu4ping2/, vinegar bottle } \\
\text { 借条, /jie4tiao2/, receipt for a loan } \\
\text { 汤勺,/tang1shao2/, spoon } \\
\text { 杨柳, /yang2liu3/, willow } \\
\text { 肠子,/chang2zi/, gut } \\
\text { 钱包,/qian2bao1/, purse } \\
\text { 线轴,/xian4zhou2/, spool } \\
\text { 栈道,/zhan4dao4/, plank road } \\
\text { 佳丽, /jia1li4/, beauty } \\
\text { 桂圆,/gui4yuan2/, longan } \\
\text { 娃娃,/wa2wa/, moppet }\end{array}$ & $\begin{array}{l}\text { 肠子, /chang2zi/, gut } \\
\text { 醋瓶,/cu4ping2/, vinegar bottle } \\
\text { 桂圆,/gui4yuan2/, longan } \\
\text { 蜡烛, /la4zhu2/, candle } \\
\text { 线轴,/xian4zhou2/, spool } \\
\text { 佳丽, /jia1li4/, beauty } \\
\text { 借条, /jie4tiao2/, receipt for a loan } \\
\text { 栈道,/zhan4dao4/, plank road } \\
\text { 汤勺,/tang1shao2/, spoon } \\
\text { 杨柳, /yang2liu3/, willow } \\
\text { 娃娃,/wa2wa/, moppet } \\
\text { 钱包, /qian2bao1/, purse }\end{array}$ \\
\hline
\end{tabular}

(Manuscript received June 30, 2008;

revision accepted for publication February 7, 2009.) 